\title{
Synthesis and Properties of New Organosoluble Alkoxylated Naphthalene-Based Novolacs Preparaed by Addition-Condensation of Mono- or Di-alkoxynaphthalene with Formaldehyde
}

\author{
By Tadamasa NEMOTO and Gen-ichi KONISHI*
}

The preparation of new alkoxylated naphthalene-based novolacs [poly(naphthylenemethylene)s] by acid-catalyzed additioncondensation of mono- or di-methoxynaphthalene with formaldehyde is described in this paper. The polymerization of 2 methoxynaphthelene (1) with an equimolar amount of formaldehyde proceeded homogeneously to give the polymer $\mathbf{2}\left(M_{\mathrm{n}}\right.$ $\left.3100, M_{\mathrm{w}} / M_{\mathrm{n}} 1.7\right)$ in good yield. The FT-IR, ${ }^{1} \mathrm{H}$ NMR and ${ }^{13} \mathrm{C}$ NMR spectra suggest that 2 might have a naphthylenemethylene unit and approximately linear polymer backbones. In contrast, in the case of 1,5-dimethoxynaphthalene (3a) as a monomer, the obtained polymer $(4 \mathbf{a})\left(M_{\mathrm{n}} 1900, M_{\mathrm{w}} / M_{\mathrm{n}} 2.3\right)$ was a branched polymer. From TGA, $T_{10}$ (temperature at $10 \%$ loss in weight) indexes of the polymers 2 and $4 \mathbf{a}$ were estimated to be 402 and $359^{\circ} \mathrm{C}$, respectively. These results indicate that the alkoxylated naphthalene-based novolacs have good thermal stability.

KEY WORDS: Phenolic Resin / Novolac / Addition-Condensation / Naphthalene / Alkoxynaphthalene / Thermal Property /

Novolacs (phenolic resins) ${ }^{1}$ and their related polymers ${ }^{2}$ have attracted the attention of many researchers. These polymers are excellent materials in terms of moisture resistance, heat tolerance, and electrical properties; therefore, these polymers are used in industries related to adhesives, photoresists, polymer blends, cures, etc. ${ }^{1,3}$ It is said that these characteristic features are derived from a rigid rod-like poly(phenylenemethylene) backbone; ${ }^{4}$ however, little is known regarding the synthesis of new functional aromatic polymers from this viewpoint. Recently, we have reported the preparation of organosoluble poly(phenylenemethylene)s for the purpose of developing novel functional novolacs. ${ }^{4-6}$ These polymers were well-soluble in common organic solvents such as chloroform, tetrahydrofuran (THF), and toluene. As compared to the common novolacs, alkoxylated novolacs, which have good processability, are more stable to heat, acid, and oxidation due to the protection of a phenolic hydroxyl group. However, the molecular weights of these poly(phenylenemethylene)s are not significantly high, and their mechanical properties are not remarkable. In order to improve their physical properties, particularly thermal stability, and produce high-performance novolacs by enhancing the aromaticity of the polymer, we focused on the naphthalene moiety. The introduction of a naphthalene moiety to the polymer in the main or side chain can enhance its thermal stability, crystallinity, or processability. ${ }^{7-10}$ Naphthalene-containing polymers have considerable potential for use in materials and are expected to be developed for application to new materials, e.g., carbon fibers, and nano-sized additives for the polymer materials.
In this paper, we report the addition-condensation of mono- and di-methoxynaphthalene, or diethoxynaphthalene with formaldehyde for the preparation of organosoluble alkoxylated naphthalene-based novolacs. It is expected that the poly(naphthylenemethylene)s, which are soluble in organic solvents, will exhibit high molecular weights and regular polymer backbones.

\section{EXPERIMENTAL}

\section{Instruments}

All the ${ }^{1} \mathrm{H}$ NMR, ${ }^{13} \mathrm{C}$ NMR spectra were obtained in $\mathrm{CDCl}_{3}$ and recorded by a $400 \mathrm{MHz}$ JEOL LNM-EX400 instrument with tetramethylsilane (TMS) as the internal standard. The FTIR spectra were recorded using a JASCO FT-IR 460 plus spectrometer. Gel permeation chromatography (GPC) was carried out by a JASCO UV-2070 detector and a JASCO RI-2031 detector (TOSOH TSK-gel GMH-HR column) using tetrahydrofuran (THF) as an eluent after calibration with standard polystyrenes. Thermogravimetric analysis (TGA) was performed using a SII TG/DTA 6200 with a heating rate of $10^{\circ} \mathrm{C} / \mathrm{min}$ under a nitrogen atmosphere. Differential scanning calorimetry (DSC) was carried out on a SII DSC 6220 at a heating rate of $10^{\circ} \mathrm{C} / \mathrm{min}$ under a nitrogen atmosphere.

\section{Materials \\ Unless otherwise noted, all reagents and chemicals were purchased from Wako Pure Chem. and used without further purifications. Paraformaldehyde $(95 \%)$ was obtained from Nacalai Tesque. 2-Methoxynaphthalene (1), 1,5-dihydroxy-}


naphthalene and sodium hydride were purchased from TCI. 1,5-Dimethoxynaphthalene (3a), 2,6-dimethoxynaphthalene (3b), 2,7-dimethoxynaphthalene (3c), 1,5-diethoxynaphthalene (5a), 2,6-diethoxynaphthalene (5b), 2,7-diethoxynaphthalene (5c) were prepared according to a Williamson ether synthesis method.

\section{Addition-condensation of 2-Methoxynaphthalene (1) with Formaldehyde}

The preparation of 2-methoxynaphthalene (1) novolac was carried out by the sulfuric acid-catalyzed addition-condensation of 2-methoxynaphthalene with formaldehyde. 2-Methoxynaphthalene $(1.6 \mathrm{~g}, 10 \mathrm{mmol})$ and paraformaldehyde $(0.30 \mathrm{~g}$, $10 \mathrm{mmol}$ as a formaldehyde unit) were added in the acetic acid $(10 \mathrm{~mL}) /$ chloroform $(10 \mathrm{~mL})$ mixture at room temperature. After stirring for a few minutes, $1.0 \mathrm{~mL}$ of conc. sulfuric acid was added dropwise to the mixture at $0^{\circ} \mathrm{C}$. The resulting mixture was stirred and heated at $60^{\circ} \mathrm{C}$ for $30 \mathrm{~min}$. After cooling to room temperature, the mixture was poured into methanol $(200 \mathrm{~mL})$, and collected the crude product. The crude product was dissolved in THF and reprecipitated into methanol to give the polymer (2).

${ }^{1} \mathrm{H}$ NMR (400 MHz, $\left.\delta(\mathrm{ppm}), \mathrm{CDCl}_{3}\right)$ : 3.02-4.01 ( $\left.\mathrm{Ar}-\mathrm{OCH}_{3}\right)$, 4.24-4.83 (Ar- $\mathrm{CH}_{2}-\mathrm{Ar}$ ), 6.92-7.95 (aromatic $\mathrm{H}$ ).; ${ }^{13} \mathrm{C} \mathrm{NMR}$ (100 MHz, $\left.\delta(\mathrm{ppm}), \mathrm{CDCl}_{3}\right):$ 29.4-31.5 (Ar-CH$\left.-\mathrm{Ar}\right), 55.4-$ $56.9\left(-\mathrm{OCH}_{3}\right), 113.3$ (aromatic $C_{1}-\mathrm{CH}_{2}-$ ), 118.0-137.5 (aromatic C), 153.8-155.2 (aromatic $\left.C-\mathrm{OCH}_{3}\right)$; FT-IR $(\mathrm{KBr}$, $\mathrm{cm}^{-1}$ ): 3068 (aromatic C-H), 2935 (methylene C-H), 1091 (C-O-C), 889 (isolated $\mathrm{H}$ of an aromatic $\mathrm{C}-\mathrm{H}$ ), 810 (adjacent $2 \mathrm{H}$ of an aromatic $\mathrm{C}-\mathrm{H}$ ), 747 (adjacent $4 \mathrm{H}$ of an aromatic C-H).; GPC (RI detector, polystyrene standards): $M_{\mathrm{n}}=3100$, $M_{\mathrm{w}}=5300, M_{\mathrm{w}} / M_{\mathrm{n}}=1.7$.

\section{Addition-condensation of Di-Substituted Naphthalene (3a-} 3c, 5a-5c) with Formaldehyde

The two typical polymerization procedures via the additioncondensation reaction were as follows.

Method A. Di-substituted naphthalene $(1.0 \mathrm{mmol})$ and paraformaldehyde $(0.30 \mathrm{~g}, 1.0 \mathrm{mmol}$ as a formaldehyde unit) were added into the chloroform $(3.0 \mathrm{~mL})$ and acetic acid $(1.0 \mathrm{~mL})$ mixture; then, conc. $\mathrm{H}_{2} \mathrm{SO}_{4}(0.20 \mathrm{~mL})$ was added dropwise to the reaction mixture at $0{ }^{\circ} \mathrm{C}$. After stirring at $0{ }^{\circ} \mathrm{C}$ for $10 \mathrm{~min}$, the mixture continued to be stirred at room temperature for $50 \mathrm{~min}$. The mixture was poured into excess amount of methanol to give a crude product. A soluble and an insoluble part in chloroform were collected separately, the objective product was gained.

Method B. Dialkoxynaphthalene $(1.0 \mathrm{mmol})$ and paraformaldehyde $(0.30 \mathrm{~g}, 1.0 \mathrm{mmol}$ as a formaldehyde unit $)$ were added into the $o$-dichlorobenzene $(6.0 \mathrm{~mL})$ and acetic acid $(2.0 \mathrm{~mL})$ mixture; then, $12 \mathrm{~N} \mathrm{HCl}$ aq. $(0.20 \mathrm{~mL})$ was added to the reaction mixture slowly at $0^{\circ} \mathrm{C}$. After stirring at $0^{\circ} \mathrm{C}$ for $10 \mathrm{~min}$, the mixture continued to be stirred at $100^{\circ} \mathrm{C}$ for $50 \mathrm{~min}$. By cooling the mixture to room temperature, the reaction mixture was poured into excess methanol to give a crude product. The crude product was dissolved in chloroform

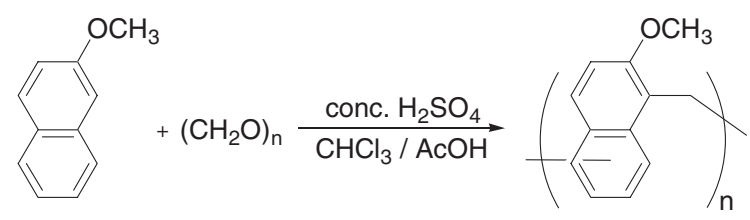

Scheme 1. Addition-condensation of 2-methoxynaphthalene (1) with formaldehyde.

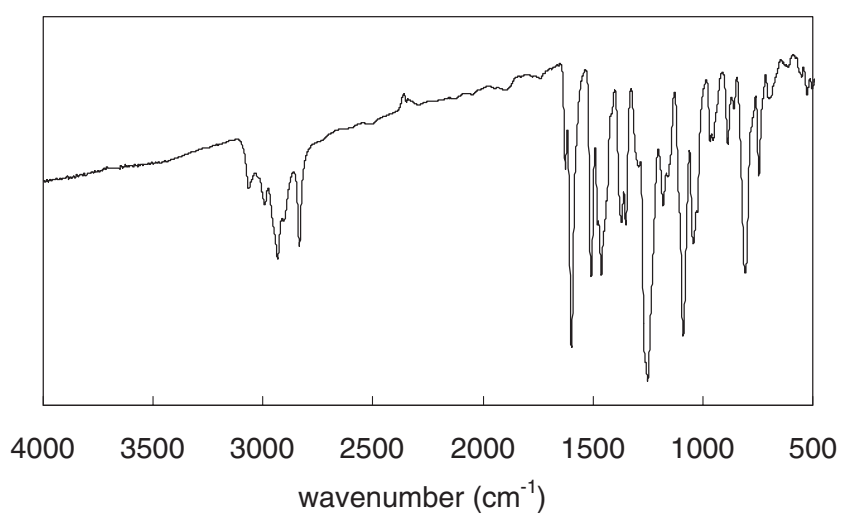

Figure 1. FT-IR spectrum of 2-methoxynaphthylene novolac (2) in $\mathrm{KBr}$.

and reprecipitated into methanol to give the objective polymer as a powder.

\section{RESULTS AND DISCUSSION}

\section{Addition-condensation of 2-Methoxynaphthalene (1) with Formaldehyde}

The polymerization of 2-methoxynaphthalene (1) with formaldehyde using conc. $\mathrm{H}_{2} \mathrm{SO}_{4}$ as a catalyst proceeded homogeneously (Scheme 1). An organosoluble polymer (2) was obtained as a colorless precipitate in $95 \%$ yield. In the FTIR spectrum, two typical peaks derived from the methylene and methoxy moieties appeared at 2935 and $1091 \mathrm{~cm}^{-1}$, respectively (Figure 1). In the ${ }^{1} \mathrm{H} \mathrm{NMR}$ spectrum, the peaks of methylene bridge and methoxy protons appeared at 4.24-4.83 and 3.02-4.01 ppm, respectively. The ${ }^{13} \mathrm{C}$ NMR spectrum showed that the peaks of the methylene bridge and methoxy group appeared at 29.4-31.5 and 55.4-56.9 ppm, respectively (Figure 2). These results indicate that the polymer $\mathbf{2}$ had an arylene-methylene-arylene formation and a methoxy moiety. From the gel permeation chromatography (GPC) analysis, the number-average molecular weight $\left(M_{\mathrm{n}}\right)$ and the polydispersity index $\left(M_{\mathrm{w}} / M_{\mathrm{n}}\right)$ of the polymer were estimated to be 3100 and 1.7, respectively. These results suggest that the polymer 2 is poly(naphthylenemethylene).

Further details of the polymer structure were obtained from the FT-IR and ${ }^{13} \mathrm{C}$ NMR spectra. From the FT-IR spectrum of 2, the peaks at $889 \mathrm{~cm}^{-1}$ (isolated $\mathrm{H}$ of an aromatic $\mathrm{C}-\mathrm{H}$ ), $810 \mathrm{~cm}^{-1}$ (adjacent $2 \mathrm{H}$ of an aromatic $\mathrm{C}-\mathrm{H}$ ), and $747 \mathrm{~cm}^{-1}$ (adjacent $4 \mathrm{H}$ of an aromatic $\mathrm{C}-\mathrm{H}$ ) appeared around a figureprint region. Furthermore, from the ${ }^{13} \mathrm{C}$ NMR spectrum, the singlet peak derived from the $\mathbf{C}_{\mathbf{1}}$ carbon appeared at 


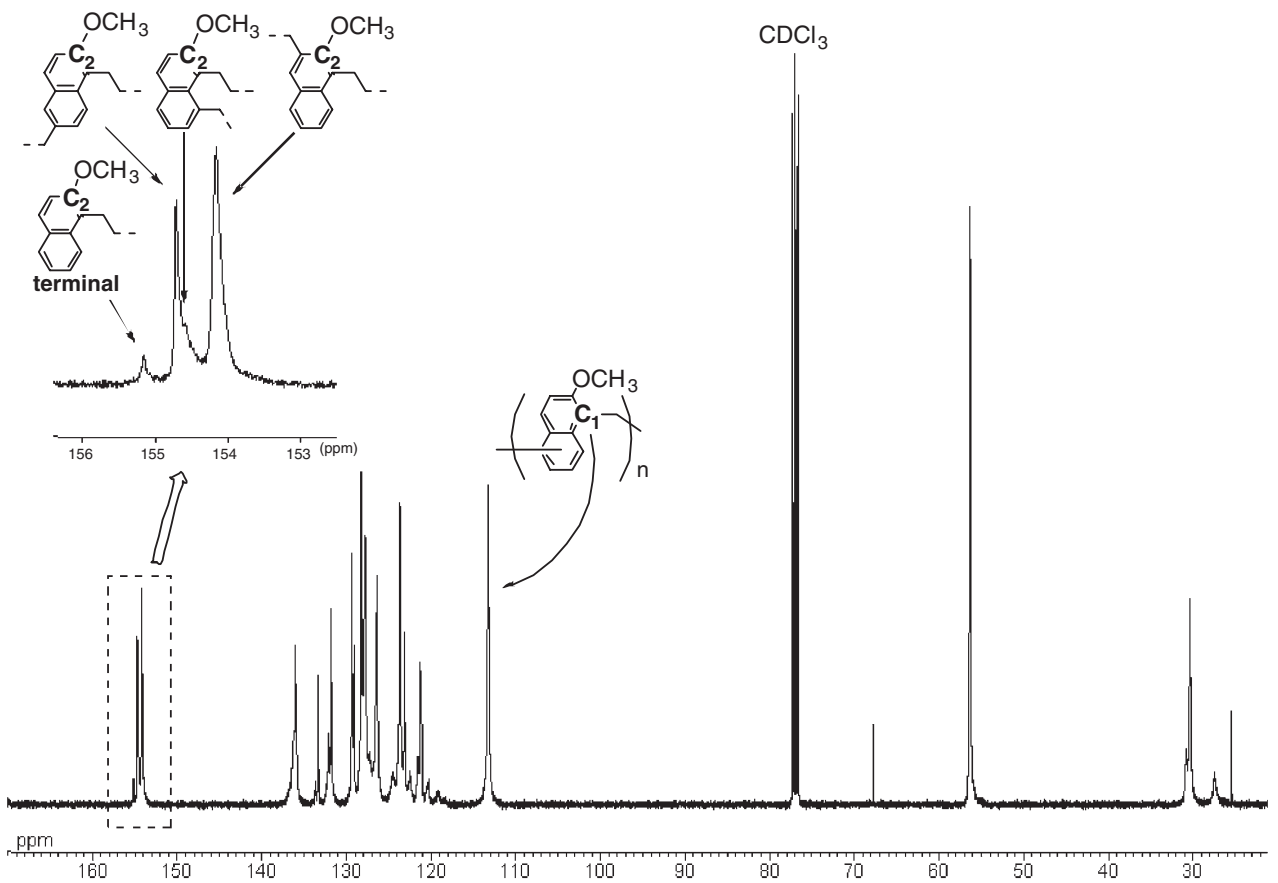

Figure 2. ${ }^{13} \mathrm{C}$ NMR spectra of 2-methoxynaphthylene novolac (2) in $\mathrm{CDCl}_{3}$ (inset: detailed assignment of the $\mathbf{C}_{2}$-position).

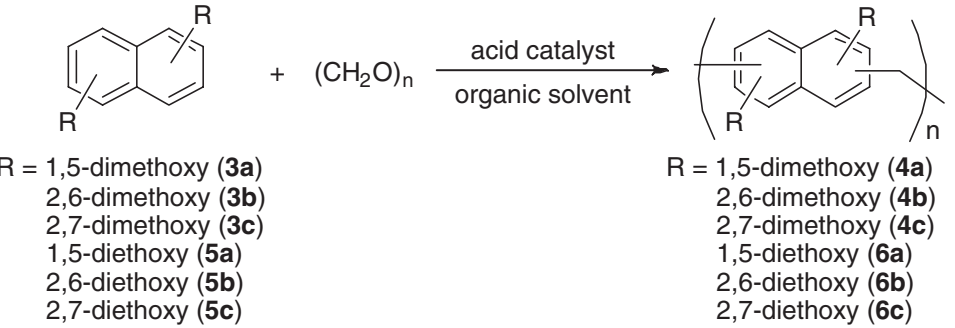

Scheme 2. Addition-condensation of dialkoxynaphthalene (3a-3c, 5a-5c) with formaldehyde.

$113.3 \mathrm{ppm}$, and the presence of nonreacted $\mathbf{C}_{\mathbf{1}}$ carbon could not be confirmed. This indicates that the addition-condensation between 2-methoxynaphthalene and formaldehyde definitely occurred at the $\mathbf{C}_{\mathbf{1}}$-position; then, the additional reaction occurred not only at the $\mathbf{C}_{\mathbf{3}}$-position but also at other carbon positions, particularly at $\mathbf{C}_{6}$ and $\mathbf{C}_{8}$, because the naphthalene units had several reactive sites. This explanation is supported by the appearance of the peaks of the $\mathbf{C}_{2}$ carbon, which did not appear at $153.8-155.2 \mathrm{ppm}$ as a singlet. From the inset in Figure 2, the four kinds of the peaks from $\mathbf{C}_{2}$ carbons appeared at $155.2 \mathrm{ppm}, 154.8 \mathrm{ppm}, 154.6 \mathrm{ppm}$, and $154.2 \mathrm{ppm}$, respectively. These results indicate that 2-methoxynaphthalene reacted with formaldehyde at two positions on a naphthalene ring, i.e., at the $\mathbf{C}_{\mathbf{1}^{-}}$and $\mathbf{C}_{\mathbf{3}^{-}}$or $\mathbf{C}_{6^{-}}$or $\mathbf{C}_{\mathbf{8}}$-positions. This implies that the polymer $\mathbf{2}$ had approximately linear backbones.

The addition-condensation of 2-methoxynaphthalene (1) with 1.5 equivalent of formaldehyde afforded the polymer $\mathbf{2}^{\prime}$ in $94 \%$ yield. The $M_{\mathrm{n}}$ and $M_{\mathrm{w}} / M_{\mathrm{n}}$ of the polymer were 5100 and 2.3 , respectively. On increasing the ratio of formaldehyde from 1.5 to 2.0 , a precipitate appeared during the polymerization.
These results indicate that the addition-condensation reactions were enhanced by the increase in the ratio of formaldehyde; however, a branching reaction also occurred. As compared to the hydroxyl group-masked polymer 2, the 2-hydroxynaphthalene novolac is a low molecular weight oligomer or a network polymer. Also, this novolac has been used only as a curing agent. ${ }^{11}$ Therefore, the polymer structure of naphthol novolac will not be discussed in detail. The result indicates that the polymer $\mathbf{2}$ has good solubility in organic solvents and a high molecular weight due to the protection of the hydroxyl group. ${ }^{6}$

\section{Addition-condensation of Dialkoxynaphthalene (3a-3c, 5a- 5c) with Formaldehyde}

To discuss the reactive position of the substituted naphthalene, particularly with formaldehyde, the acid-catalyzed polymerization of dialkoxynaphthalene with formaldehyde was performed (Scheme 2). The results of the polymerization of dialkoxynaphthalenes with formaldehyde are summarized in Table I. When the addition-condensations of $\mathbf{3 a - 3 c}$ with formaldehyde were carried out according to $\operatorname{Method~A,~as~}$ 
Table I. Addition-condensation of dialkoxynaphthalene (3a-3c, 5a-5c) with formaldehyde

\begin{tabular}{|c|c|c|c|c|c|c|c|c|}
\hline run & substrate & method & solvent $(\mathrm{mL})$ & acid & time & temp. & yield $(\%)^{* 2}$ & $M_{\mathrm{n}}\left(M_{\mathrm{w}} / M_{\mathrm{n}}\right)^{* 4}$ \\
\hline 1 & $3 a$ & A & $\mathrm{CHCl}_{3} 3 / \mathrm{AcOH} 1$ & conc. $\mathrm{H}_{2} \mathrm{SO}_{4}$ & $1 \mathrm{~h}$ & r.t. & N.D. ${ }^{* 3}$ & - \\
\hline 2 & $3 b$ & A & $\mathrm{CHCl}_{3} 3 / \mathrm{AcOH} 1$ & conc. $\mathrm{H}_{2} \mathrm{SO}_{4}$ & $1 \mathrm{~h}$ & r.t. & N.D. ${ }^{* 3}$ & - \\
\hline 3 & $3 c$ & A & $\mathrm{CHCl}_{3} 3 / \mathrm{AcOH} 1$ & conc. $\mathrm{H}_{2} \mathrm{SO}_{4}$ & $1 \mathrm{~h}$ & r.t. & N.D. ${ }^{* 3}$ & - \\
\hline 4 & $3 a$ & B & $\mathrm{DCB}^{* 1} 3 / \mathrm{AcOH} 1$ & $12 \mathrm{~N} \mathrm{HCl}$ aq. & $1 \mathrm{~h}$ & $100^{\circ} \mathrm{C}$ & 77 & $1900(2.3)$ \\
\hline 5 & $3 b$ & B & $\mathrm{DCB}^{* 1} 3 / \mathrm{AcOH} 1$ & $12 \mathrm{~N} \mathrm{HCl}$ aq. & $1 \mathrm{~h}$ & $100^{\circ} \mathrm{C}$ & N.D. $* 3$ & - \\
\hline 6 & $3 c$ & B & $\mathrm{DCB}^{* 1} 3 / \mathrm{AcOH} 1$ & $12 \mathrm{~N} \mathrm{HCl}$ aq. & $1 \mathrm{~h}$ & $100^{\circ} \mathrm{C}$ & $36 * 4$ & $660(1.2)^{* 4}$ \\
\hline 7 & $5 a$ & A & $\mathrm{CHCl}_{3} 3 / \mathrm{AcOH} 1$ & conc. $\mathrm{H}_{2} \mathrm{SO}_{4}$ & $1 \mathrm{~h}$ & r.t. & $38^{* 4}$ & $3200(2.0)^{* 4}$ \\
\hline 8 & $5 b$ & A & $\mathrm{CHCl}_{3} 3 / \mathrm{AcOH} 1$ & conc. $\mathrm{H}_{2} \mathrm{SO}_{4}$ & $1 \mathrm{~h}$ & r.t. & N.D. ${ }^{* 3}$ & - \\
\hline 9 & $5 c$ & A & $\mathrm{CHCl}_{3} 3 / \mathrm{AcOH} 1$ & conc. $\mathrm{H}_{2} \mathrm{SO}_{4}$ & $1 \mathrm{~h}$ & r.t. & $22^{* 4}$ & $3100(1.4)^{* 4}$ \\
\hline 10 & $5 a$ & B & $\mathrm{DCB}^{* 1} 3 / \mathrm{AcOH} 1$ & $12 \mathrm{~N} \mathrm{HCl}$ aq. & $1 \mathrm{~h}$ & $100^{\circ} \mathrm{C}$ & 79 & 2200 (1.9) \\
\hline
\end{tabular}

${ }^{* 1}$ : $\mathrm{DCB}=0$-dichlorobenzene. ${ }^{* 2}$ : Isolated yield after precipitaion in methanol. ${ }^{* 3}$ : Not determined. ${ }^{* 4}$ : Soluble part in organic solvents. *5: Measured by GPC with polystyrene standards (eluent: THF).

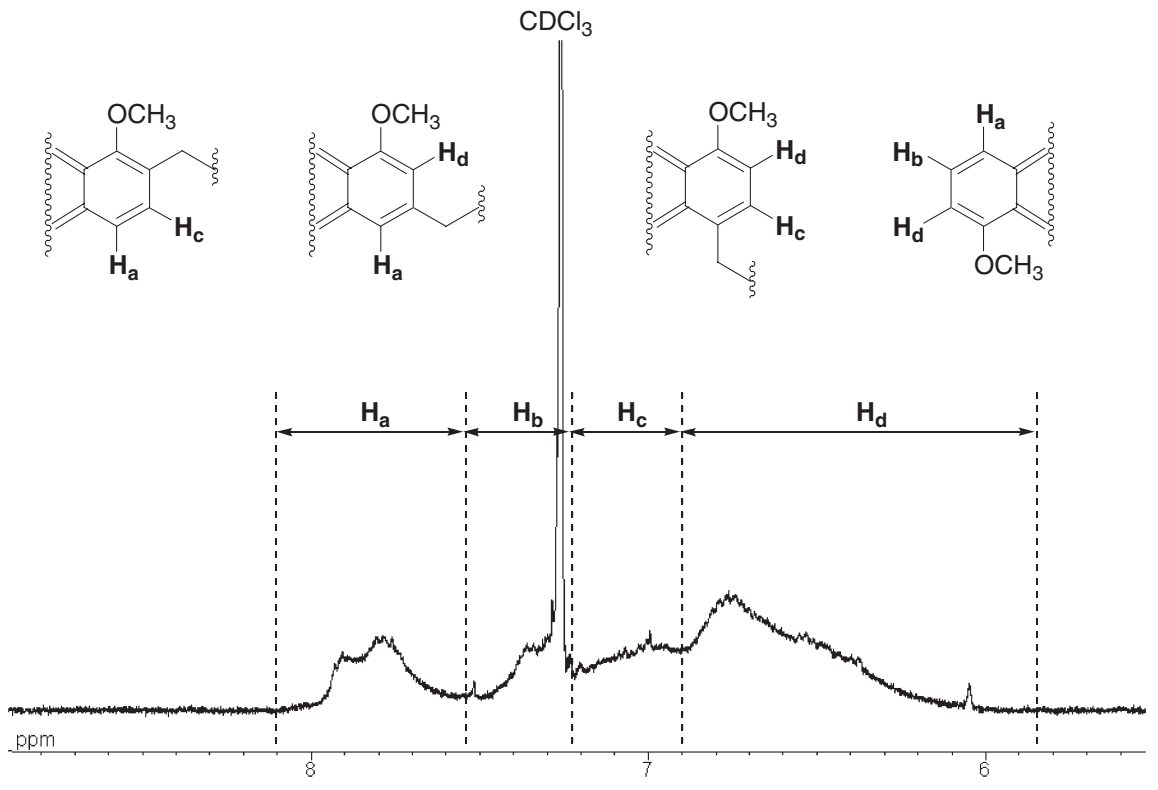

Figure 3. ${ }^{1} \mathrm{H}$ NMR spectrum of 1,5-dimethoxynaphthylene novolac (4a) in $\mathrm{CDCl}_{3}$ (partially).

described in the experimental section, precipitates appeared immediately after adding $\mathrm{H}_{2} \mathrm{SO}_{4}$ as an acid catalyst (Table I, runs 1-3). These results indicate that $\mathrm{H}_{2} \mathrm{SO}_{4}$ acid was too strong to suppress the formation of the branching structure during the addition-condensation between the substituted naphthalenes and formaldehyde.

To control the strength of acid and the solubility of the polymer, we carried out the addition-condensation of 1,5dimethoxynaphthalene (3a) with formaldehyde by using Method B (Table I, run 4). The polymerization proceeded homogeneously during the reaction. After stirring for $1 \mathrm{~h}$, the reaction mixture was poured into an excess amount of methanol to obtain the polymer $\mathbf{4 a}$ as a precipitate. The FTIR spectrum of $4 \mathbf{a}$ showed typical peaks at $3072 \mathrm{~cm}^{-1}$ (aromatic C-H), $2940 \mathrm{~cm}^{-1}$ (methylene C-H), and $1077 \mathrm{~cm}^{-1}$ (C-O-C). In the ${ }^{1} \mathrm{H}$ NMR spectrum, the peaks of the methoxy and methylene protons were observed at 2.86-4.23 and 4.24$5.43 \mathrm{ppm}$, respectively. The ${ }^{13} \mathrm{C}$ NMR spectrum showed that the peaks of the methylene units and methoxy groups appeared at 32.8-45.4 and 52.4-64.0 ppm, respectively. From the GPC analysis, the $M_{\mathrm{n}}$ and $M_{\mathrm{w}} / M_{\mathrm{n}}$ of $\mathbf{4 a}$ were estimated to be 1900 and 2.3, respectively. These results indicate that $\mathbf{4 a}$ is poly(1,5dimethoxynaphthylenemethylene)s.

Figure 3 shows a section of the ${ }^{1} \mathrm{H}$ NMR spectrum of $\mathbf{4 a}$ derived from the polymerization of $\mathbf{3 a}$ with formaldehyde. There were many kinds of peaks from aromatic protons, so the conformation of $\mathbf{4 a}$ was complicate as shown in Figure 3. We assumed that it would be possible to polymerize 3a to obtain a linear polymer with a controlled formation under this condition; however, it was difficult to control the reaction point on the naphthalene ring irrespective of the strength of the acid. In runs 5 and 6, the polymerizations proceeded heterogeneously. This indicates that the reactivity of $\mathbf{3 b}$ and $\mathbf{3 c}$ might be higher than that of $\mathbf{3 a}$; therefore the obtained polymers were insoluble in chloroform and THF.

To improve the solubility of the naphthalene-based polymer, 1,5-diethoxynaphthalene (5a), 2,6-diethoxynaphthalene (5b), and 2,7-diethoxynaphthalene $(\mathbf{5 c})$ were subjected to the 


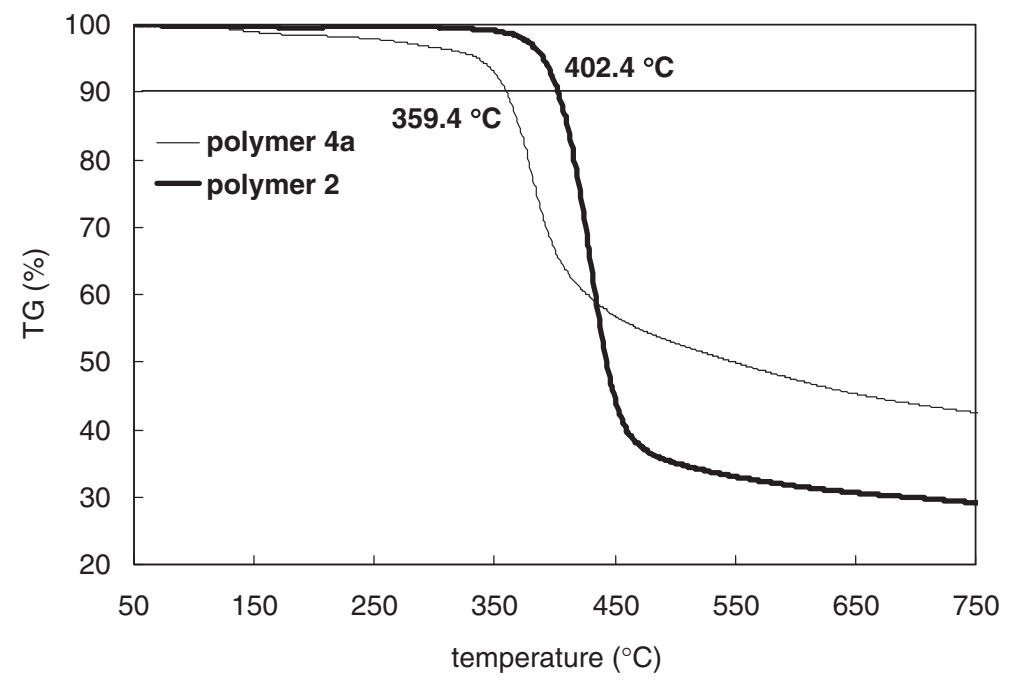

Figure 4. Thermogravimetric analyses of $\mathbf{2}$ (bold line) and $\mathbf{4 a}$ (solid line) under a nitrogen atmosphere.

addition-condensation reaction with formaldehyde. When we used Method $\mathbf{A}$ in the polymerization, precipitates appeared during the reactions (Table $I$, runs $7-9$ ). In run 10, the polymerization could be carried out in the homogeneous system; however, the yield, $M_{\mathrm{n}}$, and $M_{\mathrm{w}} / M_{\mathrm{n}}$ of the product were almost the same as those of the polymer obtained in run 4 . These results suggest that the ethyl substitutes in $\mathbf{5 a - 5 c}$ may not to be sufficient to solubilize the stiff structure.

Thus, the addition-condensation of the mono-substituted naphthalene (1) with formaldehyde could be controlled to form an approximately linear polymer backbone. On the contrary, in the cases of di-substituted naphthalenes, the reactivity of these substrates was too high to control the polymerization reaction; hence, the products were insoluble in organic solvents, or a dense network of multibranched polymers was formed.

\section{Thermal Properties}

The thermal stability of the polymers $(\mathbf{2}, \mathbf{4 a})$ was measured by TGA under a nitrogen atmosphere (Figure 4). The temperature at $10 \%$ loss in weight $\left(T_{10}\right)$ of the polymers 2 and $\mathbf{4 a}$ were 402.4 and $359.4{ }^{\circ} \mathrm{C}$, respectively; this indicates that the alkoxylated naphthalene-based novolacs showed the higher thermal stability than the organosoluble benzene-based novolacs. ${ }^{5}$ From the ${ }^{1} \mathrm{H}$ NMR and ${ }^{13} \mathrm{C}$ NMR spectra of the polymer $\mathbf{2}$, the conformation of this polymer might be similar to a linear formation; hence, this high thermal stability appears to originate from the crystallinity of the naphthalene-based backbones. However, in the differential scanning calorimetry (DSC) measurement, the glass transition point $\left(T_{\mathrm{g}}\right)$ did not appear clearly, and the melting point was not also observed. These results suggest that the polymer 2 cannot be termed to be a crystalline polymer. As the conventional phenolic resins usually have a compact form, ${ }^{5}$ the polymer 2 also might have the same morphology since this polymer exhibited the absence of a clear $T_{\mathrm{g}}$ and a non-melting point. This thermal behavior of polymer $\mathbf{2}$ is remarkable; hence, the formation of a clarification for this behavior is now in progress.

\section{CONCLUSIONS}

We have successfully prepared organosoluble alkoxylated naphthalene-based novolacs by the acid-catalyzed additioncondensation process. As compared to aromatic polymers with hydrocarbon units or phenol novolacs, the obtained polymers were well soluble in common organic solvents. The TGA revealed that organosoluble 2-methoxynaphthalene polymer (2) had the higher heat resistance than the phenol derivatives-based novolacs. However, the ${ }^{1} \mathrm{H}$ NMR and ${ }^{13} \mathrm{C}$ NMR spectra have revealed that the organosoluble 2-methoxynaphthalene polymer (2) was closer to a linear formation as compared to the 1,5dimethoxynaphthalene polymer (4a). These alkoxylated naphthalene-based novolacs can be applied in high-performance thermosetting polymers, network polymers, polymer blends, fillers, etc.

Acknowledgment. We thank Prof. Y. Nakamoto (Kanazawa University) for helpful discussion. This work was partially supported by Industrial Technology Research \& Development Grant (04A23030) from NEDO of JAPAN.

Received: February 2, 2008

Accepted: April 14, 2008

Published: June 4, 2008

\section{REFERENCES}

1. a) A. Knop and L. A. Plato, "Phenolic Resins," Springer-Verlag, Berlin, 1985.

2. a) T. Fukuoka, H. Uyama, and S. Kobayashi, Macromolecules, 36, 8213 (2003).

b) Y. Tsutsui, N. Numao, and M. Suzuki, Polym. J., 38, 234 (2006). c) T. Temma, Y. Takahashi, Y. Yoshii, and S. Habaue, Polym. J., 39, 524 (2007).

d) K. Mikame and M. Funaoka, Polym. J., 38, 585 (2006).

e) T. Agag and T. Takeichi, J. Polym. Sci., Part A: Polym. Chem., 45 , 1878 (2007). 
3. a) A. Matsumoto, K. Hasegawa, A. Fukuda, and K. Otsuki, J. Appl. Polym. Sci., 44, 1547 (1992).

b) J. Kadota, T. Fukuoka, H. Uyama, K. Hasegawa, and S. Kobayashi, Macromol. Rapid Commun., 25, 441 (2004).

c) G. Pan, Z. Du, C. Zhang, C. Li, X. Yang, and H. Li, Polym. J., 39, 478 (2007).

d) G. Konishi, T. Kimura, and Y. Nakamoto, Macromol. Res., 15, 191 (2007).

e) A. Kobayashi and G. Konishi, Polym. J., 40, 590 (2008).

4. D.-M. Shin, N. Ozeki, Y. Nakamoto, and G. Konishi, Macromol. Res., 14, 255 (2006).

5. T. Nemoto, T. Ueno, M. Nishi, D.-M. Shin, Y. Nakamoto, and G. Konishi, Polym. J., 38, 1278 (2006).

6. T. Kimura, Y. Nakamoto, and G. Konishi, Polym. J., 38, 606 (2006).

7. a) T. Inoue, Y. Mizukami, H. Okamoto, H. Matsui, H. Watanabe, T. Kanaya, and K. Osaki, Macromolecules, 29, 6240 (1996). b) J. R. Lizotte, B. M. Erwin, R. H. Colby, and T. E. Long, J. Polym. Sci., Part A: Polym. Chem., 40, 583 (2002).

8. T. Yamanobe, H. Matsuda, K. Imai, A. Hirata, S. Mori, and T. Komoto, Polym. J., 28, 177 (1996).

9. A. Yildirim, B. Kiskan, A. L. Demirel, and Y. Yagci, Eur. Polym. J., 42, 3006 (2006).

10. a) K. Tsuchiya and M. Ueda, Polym. J., 38, 956 (2006).

b) Y. Yin, O. Yamada, K. Tanaka, and K. Okamoto, Polym. J., 38, 197 (2006).

c) K. Maeyama, K. Ogura, A. Okamoto, K. Ogino, H. Saito, and N. Yonezawa, Polym. J., 38, 736 (2006).

d) T. Nemoto, G. Konishi, T. Arai, and T. Takata, Polym. J., 40, 622 (2008).

11. M. Kaji, J. Network. Polym. Jpn., 24, 36 (2003) and references cited therin. 